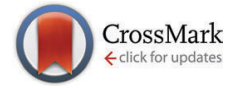

Cite this: Phys. Chem. Chem. Phys., 2016, 18, 6954

DOI: $10.1039 / \mathrm{c} 6 \mathrm{cp} 90041 \mathrm{k}$

www.rsc.org/pccp

\section{Correction: Graphene-catalyzed photoreduction of dye molecules revealed by graphene enhanced Raman spectroscopy}

\author{
Bora Lee, Jin Hyoun Kang, Insu Jo, Dongha Shin* and Byung Hee Hong*
}

Correction for 'Graphene-catalyzed photoreduction of dye molecules revealed by graphene enhanced Raman spectroscopy' by Bora Lee et al., Phys. Chem. Chem. Phys., 2016, 18, 3413-3415.

The authors would like to add the following Acknowledgements:

This research was supported by the National Research Foundation of Korea funded by the Ministry of Education, Science and Technology (GRL Program 2011-0021972, 2011-0017587).

The Royal Society of Chemistry apologises for these errors and any consequent inconvenience to authors and readers. 